\title{
Ensino Híbrido: Proposta de formação de professores para uso integrado das tecnologias digitais nas ações de ensino e aprendizagem
}

\author{
Lilian Bacich ${ }^{1}$ \\ Instituto Península, lilian.bacich@usp.br
}

\begin{abstract}
Resumo. As tecnologias digitais podem colaborar com os processos de ensino e aprendizagem, porém apenas o uso da tecnologia não é suficiente. O Ensino Hibrido, que combina o uso da tecnologia digital com as interações presenciais, é um modelo possivel para facilitar a combinação do ensino online com o ensino presencial. Nesse sentido, Instituto Península e Fundação Lemann organizaram um Grupo de Experimentações, com uma amostra de dezesseis educadores de diferentes estados brasileiros de escolas públicas e particulares. Os resultados obtidos a partir de análises de planos de aula, vídeos e texto elaborado pelos professores indicam enriquecimento da prática pedagógica por meio de abordagem metodológica com o uso integrado das tecnologias digitais visando a personalização.
\end{abstract}

\section{Introdução}

O estudo sobre o uso das tecnologias digitais no processo ensino-aprendizagem não é recente na educação. Desde o final do século passado, com a introdução do uso dos computadores na escola, diversos estudos têm sido realizados com o objetivo de identificar estratégias e consequências dessa utilização. O envolvimento das instituições de ensino, professores e demais profissionais da educação nesse processo de implementação das tecnologias digitais é considerado um desafio e discussões sobre o tema são recorrentes em diferentes instâncias. Dentre as diferentes propostas de implementação do uso das tecnologias digitais no processo ensino-aprendizagem, o modelo denominado Ensino Híbrido é apresentado neste texto.

É possível encontrar diferentes definições para Ensino Híbrido na literatura. Todas elas apresentam, de forma geral, a convergência de dois modelos de aprendizagem: o modelo presencial, em que o processo ocorre em sala de aula, como vem sendo realizado há tempos, e o modelo online, que utiliza as tecnologias digitais para promover o ensino. No modelo híbrido, a ideia é que educadores e estudantes ensinem e aprendam em tempos e locais variados. Principalmente no Ensino Superior, esse modelo de ensino está atrelado a uma metodologia de ensino a distância $(\mathrm{EaD})$, em que o modelo tradicional, presencial, se mistura com o ensino a distância e, em alguns casos, algumas

\footnotetext{
${ }^{1}$ Doutora em Psicologia Escolar e do Desenvolvimento Humano pela Universidade de São Paulo (USP), Mestre em Educação pela Pontifícia Universidade Católica de São Paulo (PUC-SP). Bióloga (Mackenzie) e Pedagoga (USP). Co-organizadora do livro e coordenadora do curso online: "Ensino Hibrido: personalização e tecnologia na educação" parceria entre o Instituto Península e a Fundação Lemann.
} 
V Congresso Brasileiro de Informática na Educação (CBIE 2016)

Anais do XXII Workshop de Informática na Escola (WIE 2016)

disciplinas são ministradas na forma presencial e, outras, ministradas apenas a distância. Esse seria o uso original do termo que evoluiu para abarcar um conjunto muito mais rico de estratégias ou dimensões de aprendizagem e, entre elas, a forma proposta neste texto. O termo Ensino Híbrido está enraizado em uma ideia de que não existe uma forma única de aprender e que a aprendizagem é um processo contínuo.

O uso integrado das tecnologias digitais na Educação Básica, sua importância para a personalização do ensino e o processo de formação pelo qual deveriam passar os professores que estivessem envolvidos com essa proposta foram preocupações que estimularam a parceria entre duas organizações do terceiro setor, o Instituto Península ${ }^{2}$ e a Fundação Lemann ${ }^{3}$, na constituição de uma pesquisa conjunta envolvendo esses objetos de estudo.

O modelo utilizado nesta pesquisa, desenvolvido com apoio do Instituto Clayton Christensen $^{4}$, foi identificado como uma possível estratégia de integração das tecnologias digitais ao ensino com ênfase na personalização do ensino. Do encontro com Michael Horn ${ }^{5}$, um dos responsáveis pela proposta, decorreu a parceria entre Instituto Península, Fundação Lemann e Instituto Clayton Christensen. Trata-se do modelo Blended, traduzido para Ensino Hibrido. Eram questões a serem respondidas pelo grupo: Esse modelo, da forma como implementado nas escolas dos Estados Unidos, seria o modelo mais adequado à nossa realidade? Supondo que a proposta fosse adequada, quais as condições necessárias para envolver um grupo de professores em um processo de formação para uso desse modelo?

Assim, buscando responder a essas questões, foi organizado um encontro, com um grupo composto por professores, coordenadores, secretários de educação e empreendedores do setor educacional para coletar informações que contribuíssem para o desenho desse processo. O encontro, baseado na abordagem de Design Thinking ${ }^{6}$, apontou algumas questões que deveriam ser consideradas e que, somadas ao resultado das entrevistas realizadas nas escolas dos Estados Unidos que utilizavam o modelo, contribuiu para a constituição de um grupo de experimentação e para a abordagem

2 O Instituto Península nasce em 2010 com objetivo de canalizar em uma única frente o investimento social dos membros da família Abilio Diniz. Desta forma, recursos e esforços são potencializados em prol das causas que interessam e mobilizam a todos: educação e esporte.

3 A Fundação Lemann é uma organização sem fins lucrativos, criada em 2002 pelo empresário Jorge Paulo Lemann. Contribuir para melhorar a qualidade do aprendizado dos alunos brasileiros e formar uma rede de líderes transformadores são os grandes objetivos da instituição. Para cumprir essa missão, a Fundação aposta em uma estratégia que envolve quatro áreas complementares de atuação: inovação, gestão, políticas educacionais e talentos.

4 O Instituto Clayton Christensen é um think tank apartidário sem fins lucrativos, dedicado à inovação denominada "disruptiva". Embasado nas teorias do professor de Harvard Clayton M. Christensen, o Instituto desenvolve ferramentas exclusivas para a compreensão de muitos dos problemas mais prementes da sociedade, como educação e saúde.

5 Michael Horn, em 2008, escreveu com seu professor em Harvard, o renomado Clayton Christensen, o livro Disrupting Class: How Disruptive Innovation Will Change the Way the World Learns (Christensen, 2012), no qual abordava o nascimento de uma nova forma de fazer educação. Horn tornou-se cofundador do Innosight Institute, que em 2013 passou a se chamar Clayton Christensen Institute (http://porvir.org/porpensar/ensino-hibrido-e-unico-jeito-de-transformar-educacao/20140220).

6 http://www.dtparaeducadores.org.br/site/ 
V Congresso Brasileiro de Informática na Educação (CBIE 2016)

Anais do XXII Workshop de Informática na Escola (WIE 2016)

metodológica descrita no item a seguir. Foram, então, considerados alguns aspectos fundamentais:

\# Os professores que estariam envolvidos no processo de formação para o uso do modelo de Ensino Híbrido deveriam ser early adopters;

*A experimentação e a troca dessas experiências entre os participantes deveriam ser consideradas em todo o processo de formação;

\#O reconhecimento dos professores participantes e dos resultados da pesquisa pelos pares e pela comunidade acadêmica deveria ser um dos objetivos do processo.

\section{Ensino Híbrido: breve referência teórica}

O modelo de Ensino Híbrido, proposto pelos pesquisadores do Instituto Clayton Christensen (Christensen, Horn e Staker, 2012) e testado nas escolas norte-americanas, apresenta quatro tipos estruturantes: Rotação, Flex, A La carte, Virtual aprimorado.

A organização dos modelos de Ensino Híbrido (Horn e Staker, 2015) aborda formas de encaminhamento das aulas em que as tecnologias digitais podem ser inseridas de forma integrada ao currículo e, portanto, não são consideradas como um fím em si mesmas, mas têm um papel essencial no processo, principalmente em relação à personalização do ensino. As propostas de Ensino Híbrido organizam-se de acordo com o esquema apresentado na Figura 1 e serão discutidas a seguir.

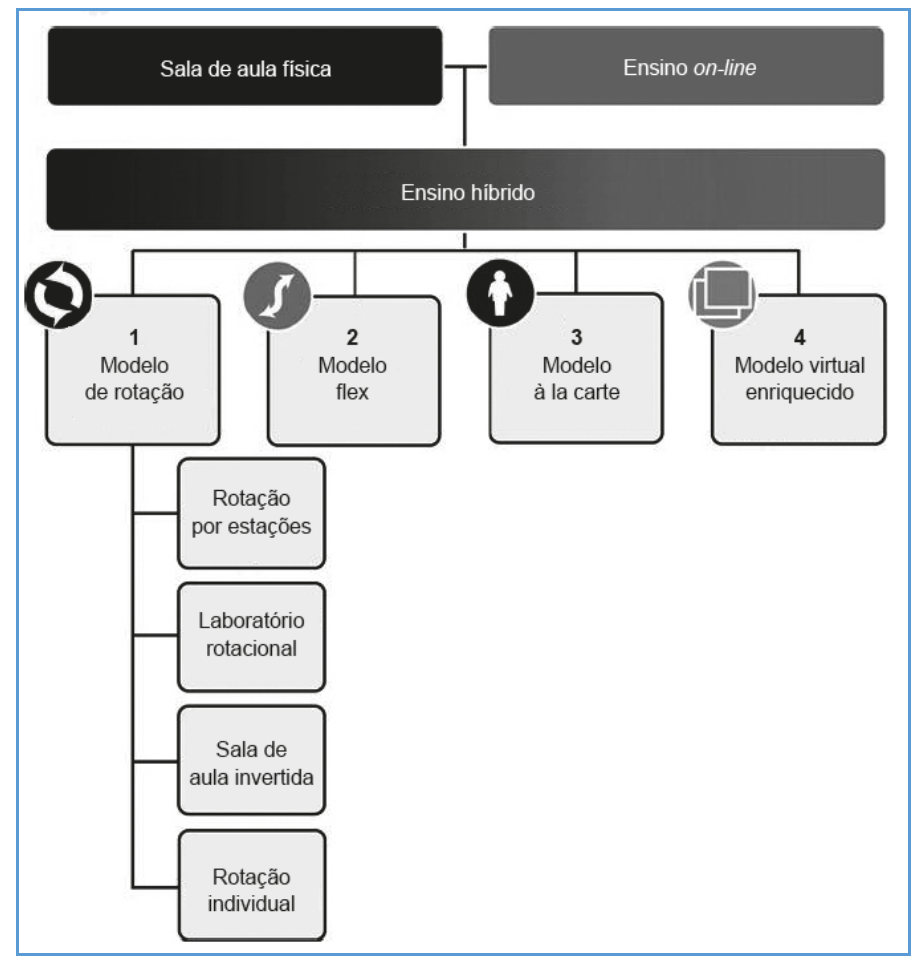

Figura 1 -Modelos de ensino híbrido - Instituto Clayton Christensen

Fonte: Horn e Staker (2015. p.38). 
Modelos de rotação: nesse modelo, os estudantes revezam as atividades realizadas de acordo com um horário fixo ou de acordo com a orientação do professor. As tarefas podem envolver discussões em grupo, com ou sem a presença do professor, atividades escritas, leituras e, necessariamente, uma atividade on-line. Nesse modelo, há as seguintes propostas:

- Rotação por estações: os estudantes são organizados em grupos e cada um desses grupos realiza uma tarefa de acordo com os objetivos do professor para a aula em questão. O planejamento desse tipo de atividade não é sequencial e as atividades realizadas nos grupos são, de certa forma, independentes, mas funcionam de forma integrada para que, ao final da aula, todos tenham tido a oportunidade de ter acesso aos mesmos conteúdos.

- Laboratório rotacional: neste modelo, os estudantes usam o espaço da sala de aula e laboratórios. O modelo de Laboratório Rotacional começa com a sala de aula tradicional, em seguida adiciona uma rotação para um computador ou laboratório de ensino. Os laboratórios rotacionais frequentemente aumentam a eficiência operacional e facilitam o aprendizado personalizado, mas não substituem o foco nas ações convencionais que ocorrem em sala de aula. $\mathrm{O}$ modelo não rompe com o ensino considerado tradicional, mas usa o ensino online como uma ação sustentada para atender melhor às necessidades dos estudantes.

- Sala de aula invertida: nesse modelo, a teoria é estudada em casa, no formato online, e o espaço da sala de aula é utilizado para discussões, resolução de atividades, entre outras propostas. O que era feito na sala de aula (explicação do conteúdo) é agora feito em casa e, o que era feito em casa (aplicação, atividades sobre o conteúdo), é agora feito em sala de aula. Esse modelo é valorizado como a porta de entrada para o Ensino Híbrido e há um estímulo para que o professor não acredite que essa é a única forma e que ela pode ser aprimorada.

- Rotação individual: cada aluno tem uma lista das propostas que deve contemplar em sua rotina para cumprir os temas a serem estudados. Aspectos como avaliar para personalizar devem estar muito presentes nessa proposta, uma vez que a elaboração de um plano de rotação individual só faz sentido se tiver como foco o caminho a ser percorrido pelo estudante de acordo com suas dificuldades ou facilidades. Nesse modelo, portanto, os estudantes rotacionam, de acordo com uma agenda personalizada, por modalidades de aprendizagem. A diferença da rotação individual para outros modelos de rotação é que os estudantes não passam, necessariamente, por todas as modalidades ou estações propostas. Sua agenda diária é individual, organizada de acordo com suas necessidades. O tempo de rotação, em alguns exemplos relatados, é livre, variando de acordo com as necessidades dos estudantes.

Modelo Flex: neste modelo, os alunos também têm uma lista a ser cumprida, com ênfase na aprendizagem on-line. O ritmo de cada estudante é personalizado e o professor fica à disposição para esclarecer dúvidas. Esse modelo, apesar de ser considerado uma possibilidade metodológica no modelo de Ensino Híbrido, requer uma modificação da estrutura de organização dos alunos no ambiente escolar. O cerne dessa proposta é que os alunos podem aprender de forma colaborativa, uns com os outros, 
com o uso dos recursos on-line, independente da organização por anos ou séries.

Modelo A La Carte: o estudante é responsável pela organização de seus estudos, de acordo com os objetivos gerais a serem atingidos, organizados em parceria com o educador; a aprendizagem, que pode ocorrer no momento e local mais adequados, é personalizada. Nessa abordagem, pelo menos uma disciplina é feita inteiramente online, apesar do suporte e organização compartilhada com o professor. A parte on-line pode ocorrer na escola, em casa ou em outros locais.

Modelo virtual enriquecido: trata-se de uma experiência realizada por toda a escola, em que, em cada curso, os alunos dividem seu tempo entre a aprendizagem on-line e a presencial. Os alunos podem se apresentar, presencialmente, na escola, apenas uma vez por semana. De acordo com Horn e Staker (2015), muitos programas deste tipo tiveram início como escolas on-line e, posteriormente, desenvolveram programas híbridos para proporcionar, aos estudantes, experiências de escolas consideradas tradicionais.

É importante ressaltar que não há uma ordem estabelecida para aplicação e desenvolvimento desses modelos em sala de aula e não há hierarquia entre eles. Alguns professores utilizam essas metodologias de forma integrada, propondo uma atividade de Sala de aula invertida para a realização, na aula seguinte, de um modelo Rotação por estações (Bacich, Tanzi Neto \& Trevisani, 2015). Os autores apresentam as propostas híbridas como concepções possíveis para o uso da tecnologia na cultura escolar contemporânea, uma vez que não é necessário abandonar o que se conhece até o momento para promover a inserção de novas tecnologias em sala de aula regular, aproveitando "o melhor dos dois mundos". Assim, aprendizagem não está restrita às aulas do dia ou da semana, não está restrita às paredes da sala de aula, não está restrita à metodologia do professor, não está restrita ao ritmo da sala de aula (Horn \& Staker, 2015). Há possibilidade de personalizar o ensino por meio da utilização de diferentes recursos didáticos.

\section{Procedimentos metodológicos}

A primeira ação realizada pelas instituições parceiras foi a divulgação, nas redes sociais e nos respectivos sites, de um edital de convocação de professores da Educação Básica que desejassem experimentar propostas inovadoras com uso de tecnologias digitais em suas aulas. Como resposta a esse edital, foram submetidos 1782 planos de aula, enviados por professores de escolas públicas e privadas, de todas as etapas da Educação Básica, de diferentes estados do Brasil. Os planos foram analisados pela equipe das instituições parceiras, composta por professores e pesquisadores na área da educação, e 35 planos foram selecionados para dar continuidade ao processo, em que seria definida a participação final de 16 professores. O grupo de 35 professores, selecionados na primeira etapa do processo de seleção, teve a oportunidade, então, de participar de um workshop com Michael Horn, como continuidade do processo seletivo. Nesse workshop, o Ensino Híbrido, como implementado nas escolas dos Estados Unidos, foi apresentado, discutido e algumas estratégias foram vivenciadas pelos professores. A 
elaboração de um plano de aula, até o término do workshop, foi o objetivo dessa etapa de seleção. Ao término desse dia de trabalho, 16 professores foram selecionados e passaram a constituir o Grupo de Experimentações em Ensino Híbrido. Desse grupo de professores, 2 deles atuavam em escola pública e privada, 6 deles apenas em escola pública e 8 deles apenas em escola privada. Em relação ao nível de ensino em que atuavam, 10 deles estavam envolvidos com o Ensino Fundamental, primeira e segunda etapa, e 7 deles atuavam no Ensino Médio. Fizeram parte do grupo professores dos estados de São Paulo (11), Minas Gerais (1), Rio de Janeiro (3) e Rio Grande do Sul (1), envolvendo 10 cidades no total.

\subsection{Atividades realizadas no Grupo de Experimentações}

As atividades realizadas no Grupo de Experimentações em Ensino Híbrido tinham dois objetivos principais:

* Verificar se o modelo de Ensino Híbrido, da forma como implementado nas escolas dos Estados Unidos, seria o modelo mais adequado à nossa realidade e se os benefícios para a apendizagem, por meio da personalização do ensino, seriam identificados pelos professores brasileiros;

*Identificar estratégias de formação de professores para a utilização do modelo de Ensino Híbrido.

Aspectos como o papel do professor, a valorização e construção da autonomia do aluno, a organização do espaço escolar para o uso integrado das tecnologias digitais, a reflexão sobre qual a melhor forma de avaliar nesse processo, o envolvimento da gestão para propiciar uma mudança gradativa na cultura escolar, como visto no capítulo anterior, são temas relevantes e que deveriam estar envolvidos nessa implementação. Mas, como organizar esses temas? Consideramos a interdependência entre esses temas, como peças de uma engrenagem que se articulam com o objetivo de refletir sobre a importância de colocar o estudante e as relações pedagógicas no centro do processo.

O foco das propostas elaboradas e apresentadas ao Grupo de Experimentações em Ensino Híbrido era levar os professores a experimentarem novas formas de atuação, refletirem sobre elas e, nesse movimento, verificarem até que ponto essas formas de condução das aulas poderiam impactar nos resultados esperados em relação ao desempenho de sua turma. Tratou-se, portanto, como definido pela literatura de um processo de pesquisa-ação.

Segundo Tripp (2005, p. 445), “A pesquisa-ação educacional é principalmente uma estratégia para o desenvolvimento de professores e pesquisadores de modo que eles possam utilizar suas pesquisas para aprimorar seu ensino e, em decorrência, o aprendizado de seus alunos [...]". Ainda segundo o autor, trata-se de uma investigação em que a prática pode ser aprimorada e pode decorrer, dela, um processo de investigação e, nessa oscilação, entre a prática, a reflexão e a pesquisa, descreve-se e avalia-se uma estratégia de melhoria da prática, aprendendo-se mais, "no correr do processo, tanto a respeito da prática quanto da própria investigação.” (p.446). 
V Congresso Brasileiro de Informática na Educação (CBIE 2016)

Anais do XXII Workshop de Informática na Escola (WIE 2016)

Cabe ressaltar que as estratégias metodológicas escolhidas como instrumentos de reflexão dos professores sobre todos os aspectos envolvidos com a proposta de ensino híbrido tiveram como objetivo inverter a lógica que estamos tão acostumados na educação: em primeiro lugar, a teoria e depois, a prática. Começar pela teoria foi o que sempre se privilegiou no ensino e que está sendo, gradativamente, revisto, quando a educação passa a discutir as metodologias ativas. Podemos considerar que esse não foi apenas um processo de pesquisa-ação, mas de ação-reflexão-pesquisa, em que a teoria está presente, principalmente, no direcionamento do olhar do pesquisador que questiona sua prática e atua a partir dessa reflexão.

Optamos por apresentar "desafios" que continham algumas das propostas do modelo de implementação sugeridas pelo Instituto Clayton Christensen, porém inserimos outras ações que, de acordo com o que identificamos na revisão da literatura, seriam essenciais, como a reflexão sobre os papeis assumidos por alunos e professor em sala de aula, a organização do espaço e a reflexão sobre a importância da avaliação ser utilizada como um recurso para a personalização do ensino (Fig. 1). Esses itens e respectivos embasamentos teóricos foram discutidos no capítulo anterior.

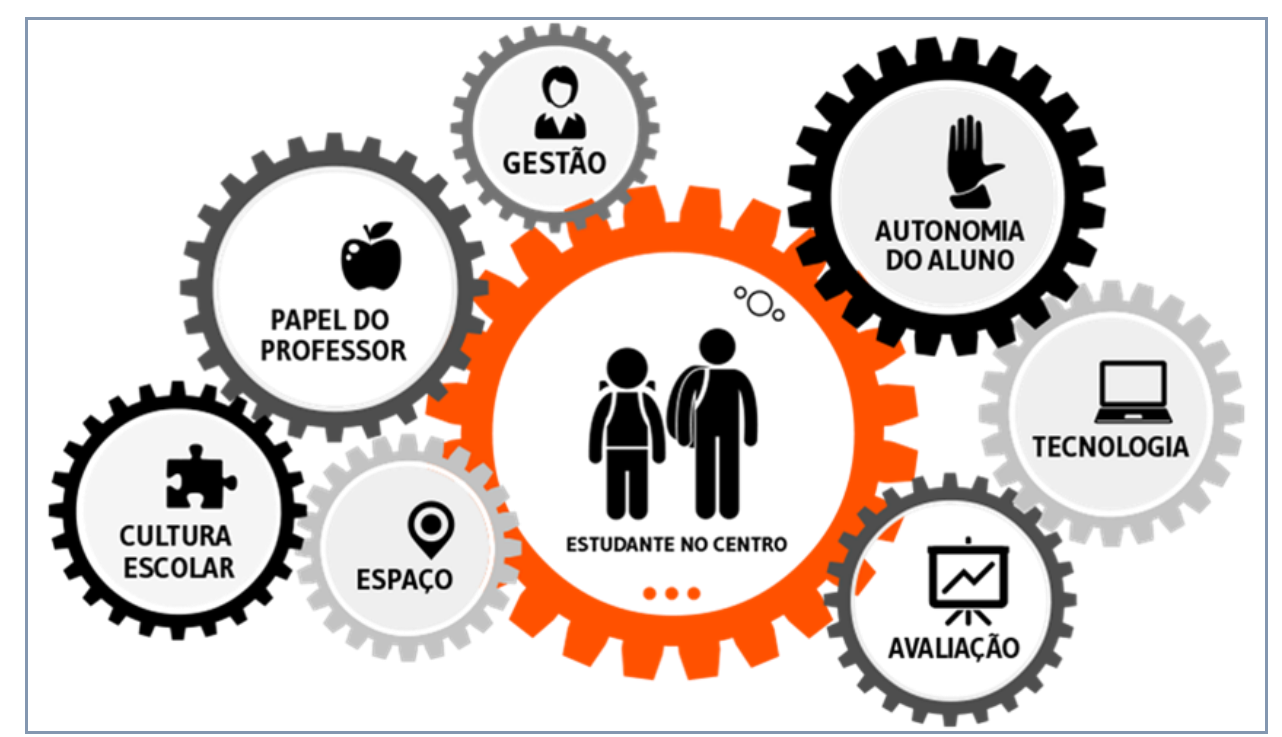

Figura 1 - Imagem elaborada para um especial do Porvir ${ }^{7}$, em que foram compartilhados cada um dos desafios elaborados para o grupo de experimentações.

Os desafios foram organizados em dois blocos, que duraram de maio a outubro. $\mathrm{O}$ primeiro bloco teve duração de 8 semanas, com um desafio proposto a cada semana, nos meses de maio e junho. O segundo bloco, que durou de agosto a outubro, também foi composto por 8 desafios, porém com período maior de execução de alguns deles,

\footnotetext{
7 http://www.porvir.org/especiais/personalizacao/ Ao clicar em "Sua vez" é possível conhecer todos os desafios propostos ao grupo de professores que fez parte do projeto, além de vídeos-depoimentos.
} 
V Congresso Brasileiro de Informática na Educação (CBIE 2016)

Anais do XXII Workshop de Informática na Escola (WIE 2016)

totalizando 12 semanas. $\mathrm{O}$ ambiente selecionado para as postagens e discussões sobre os desafios foi o Edmodo ${ }^{8}$.

Cabe ressaltar que os desafios foram elaborados semanalmente, pela pesquisadora com a validação da equipe de coordenação, de acordo com o que obtínhamos de feedback dos professores do grupo.

Dessa forma, ao término da etapa dos desafios, e devidamente embasados pela literatura, os professores finalizaram o registro das reflexões sobre: o papel do professor, o papel do estudante, o papel da gestão, as tecnologias digitais, o espaço, a avaliação, a cultura escolar. Cada um desses temas constituiu um capítulo do livro: Ensino Híbrido: personalização e tecnologia na educação, organizado pela pesquisadora e demais coordenadores do Grupo de Experimentações ${ }^{9}$. Além do livro, todos esses desafios, complementados pelas reflexões do grupo de professores, foram organizados em um curso on-line $\left(\mathrm{MOOC}^{10}\right)$, livre e gratuito, ou com tutoria, disponibilizado em duas plataformas, até o momento: plataforma do Instituto Singularidades ${ }^{11}$ e Coursera ${ }^{12}$.

\section{Resultados e discussão}

Ao pensar em multiplicar a proposta de formação de professores em outras escolas, principalmente nas escolas da rede pública, foi foco das reflexões com o grupo de professores a melhor forma de implementação do Ensino Híbrido na realidade brasileira, considerando as vantagens e os desafios por eles identificados. Um dos professores de nosso grupo afirmou: "Não há uma realidade brasileira, mas várias realidades" e concordamos com ele nesse sentido, pois sabemos que há, em nosso país, escolas em que as tecnologias digitais estão presentes em maior intensidade, com certa obrigatoriedade de uso por parte dos docentes, escolas em que as tecnologias digitais estão presentes e seu uso é facultativo, escolas em que não há tecnologias digitais, mas há entusiastas em seu uso e, ainda, escolas em que não há qualquer indício da presença ou do uso de tecnologias digitais. Nessas muitas realidades, é possível pensar em uma prática híbrida desde que ela tenha uma forma sustentada de atuação, não como uma forma puramente de ruptura em relação ao modelo de ensino considerado "tradicional", mas caminhando em direção a essa possibilidade. Uma forma sustentada de atuação envolve ações como incentivar o uso das tecnologias digitais em diferentes modelos, não apenas substituindo recursos já existentes, mas mantendo aquilo que sustenta o ensino naquela escola. Trata-se, portanto, de organizar a escola de forma a aproveitar o melhor dos dois mundos: o presencial e o on-line (Horn \& Staker, 2015). A mudança de toda uma cultura escolar não pode ser feita subitamente. Porém, em uma abordagem sustentada, ou incremental, é possível avançar para que, em determinado momento, seja

\footnotetext{
8 www.edmodo.com

9 Bacich, L.; Tanzi Neto, A. \&Trevisani, F.M. (2015). Ensino Híbrido: personalização e tecnologia na educação. Porto Alegre: Penso.

10 Curso Online Aberto e Massivo, do inglês Massive Open Online Course (MOOC).

11 www.ensinohibrido.org.br

12 www.coursera.org/learn/ensino-hibrido
} 
possível oferecer algo novo, para o qual não há comparação direta, como proposto em uma abordagem que realmente promova uma ruptura com o ensino "tradicional". Nesse aspecto, segundo a proposta do Instituto Clayton Christensen (Horn e Staker, 2015), o envolvimento das equipes da escola é fundamental. Algumas ações estão sob controle do professor que inicia a mudança em sua sala de aula. Gradativamente, desperta o interesse de outros professores da escola, que podem se envolver com a proposta e, nesse caso, é essencial o envolvimento da equipe de gestão da escola, aprovando essas modificações e avaliando o impacto dessas mudanças no ensino e na instituição.

No relato desses professores, compreendemos que, entre outras ações, a possibilidade de registrar, por meio de uma filmagem, sua atuação em sala de aula, pensar sobre ela e, depois, discuti-la com o tutor configurou-se como rico momento de aprendizado. Nesses momentos de análise do material produzido e selecionado por ele, foi possível, ao professor, confrontar-se com a imagem de seu trabalho e explicar suas ações para o tutor. Segundo Clot (2006, p.136), "a tarefa apresentada aos sujeitos consiste em elucidar para o outro e para si mesmo as questões que surgem durante o desenvolvimento das atividades com as imagens" o que, ainda segundo o autor, opera uma modificação na percepção da atividade realizada, possibilitando que ações do plano interpsicológico, por meio do diálogo com o outro, manifestem-se no plano intrapsicológico, no momento em que o sujeito, ao analisar suas ações e verbalizar sobre as condutas observadas, identifica condições de realizá-las da mesma forma ou, na maioria dos casos, de uma forma aprimorada na próxima vez.

\section{Conclusões}

De maneira geral, os aprendizados decorrentes do Grupo de Experimentações em Ensino Híbrido possibilitaram uma análise sobre a importância de estimular a reflexão, por parte do professor, sobre a organização da atividade didática. Foi possível concluir que o fato de o professor modificar as estratégias de condução da aula funcionou como disparador de reflexões sobre as relações de ensino e aprendizagem que se estabelecem em sala de aula e, consequentemente, como instrumento de análise e replanejamento de sua prática.

\section{Referências}

Bacich, L.; Tanzi Neto, A. \& Trevisani, F. de M. (2015).Ensino Híbrido: personalização e tecnologia na educação. Porto Alegre: Penso.

Clot, Y. (2006). A função psicológica do Trabalho. Petrópolis: Vozes.

Christensen, C. (2012). Inovação na sala de aula: como a inovação disruptiva muda a forma de aprender. Porto Alegre: Bookman.

Horn, M. B. \& Staker, H. (2015). Blended: usando a inovação disruptiva para aprimorar a educação. Porto Alegre: Penso.

Tripp, D. (2005). Pesquisa-ação: uma introdução metodológica. Revista Educação e Pesquisa, São Paulo, n. 3, set/dez 2005. 